\title{
Local Integration Ontological Model of Creative Class Migrants for Creative Cities
}

\author{
Korawan Sangkakorn ${ }^{1}$, Nopasit Chakpitak $^{2} \&$ Pitipong Yodmongkol ${ }^{1}$ \\ ${ }^{1}$ Knowledge Management Department, College of Arts Media and Technology, Chiang Mai University, Thailand \\ ${ }^{2}$ International College, Chiang Mai University, Thailand \\ Correspondence: Korawan Sangkakorn, College of Arts Media and Technology, Chiang Mai University, Chiang \\ Mai, Thailand. Tel: 66-89-635-0350. E-mail: korawana@hotmail.com
}

\author{
Received: May 13, 2015 Accepted: July 1, 2015 Online Published: November 26, 2015 \\ doi:10.5539/ies.v8n12p157 URL: http://dx.doi.org/10.5539/ies.v8n12p157
}

\begin{abstract}
An innovative creative class drives creative cities, urban areas in which diverse cultures are integrated into social and economic functions. The creative city of Chiang Mai, Thailand is renowned for its vibrant Lan Na culture and traditions, and draws new migrants from other areas in Thailand seeking to become part of the creative class. This study aims to classify a local integration model for the migrant creative class, and to suggest a set of indicators that could be used to measure the level of successful integration of a migrant creative class when building creative cities. This study selected twelve creative class sample cases who are well known in Chiang Mai and separated the sample into three groups; educator, researcher, and innovator. The study's agenda consisted of open-ended questions with a semi-structured format for the in-depth interview, and follows a local integration ontology model.

The study found that the local integration model consisted of four key domains: means and work, social connection, facilities, and foundations domains. Significant factors are included in each domain, and all four domains are important for the local integration of the creative class in creative cities. Annotation Ontology was used for determining the critical factors for success for migrants in creative cities: namely job, training, social bridge, and language and cultural knowledge.

This study presents a new model, the Lan Na Local Integration Metric, which can be applied to understand the successful integration of migrants into the Lan Na region of Chiang Mai.
\end{abstract}

Keywords: local integration, ontological, creative class, creative cities, migrant

\section{Introduction}

Urbanization is a multi-faceted and complicated process of social and economic changes in which a society converts from a mainly rural to a largely urban civilization (Yeates \& Garner, 1976). In observing current trends of urbanization around the globe, in 2014 North America is the most urbanized region, with $82 \%$ of its population residing in urban areas. It is followed by Latin America and the Caribbean (80\%), Europe (73\%), Asia (40\%) and Africa (40\%). However, Africa and Asia are currently urbanizing faster than the other regions, and it is speculated that these rates will increase to $56 \%$ and $64 \%$ respectively by 2050 . The rate of urbanization is significantly influenced by economic activities, including industry, commerce, and the provision of services.

In the Southeast Asian country of Thailand, the country's urban area grew from about 2,400 square kilometers to 2,700 between 2000 and 2010, demonstrating an average annual growth rate of $1.4 \%$. Urban growth in Thailand is dominated by the Bangkok metropolitan area. Bangkok, Thailand's capital city, is the fifth largest city in East Asia in terms of area and the ninth largest in terms of its population, which was approaching 10 million in 2010 (World Bank, 2015). Chiang Mai, a city nearly 700 kilometers north of Bangkok, is one of the ten biggest cities in Thailand and also one of the densest urban areas with 5,000 people per square kilometer.

While the term "urbanization" primarily refers to the process of urban growth, "urbanism" describes the consequences of urbanization; it defines the effects of city living on the behaviors, values, mores, and customs of a population (Palen, 1992). As a city possesses both cultural and social diversity, it generates a mindset where various customs and traditions can intersect (Palen, 1992). The increasing urbanization of Chiang Mai has resulted in distinctive urbanism that reflects the cultural and social heterogeneity typically seen in major 
metropolitan areas. Though some byproducts of urbanization, such as pollution, traffic, and crowding, are problematic, Chiang Mai offers economic, educational, and cultural resources that draw not only Thais, but people from around the world.

As Thailand urbanizes, the government is identifying new ways to capitalize on its rich and unique cultural heritage in an urban setting. The city of Chiang Mai is situated in the historical area of the ancient Lan Na kingdom, and still retains a great deal of Lan Na cultural influence in its architecture, food, health practices, clothing, and way of life. The people of Chiang Mai often identify as Lan Na, and speak a Lan Na dialect. The vibrant Lan Na culture has attracted tourists as well as migrants to the city, and has been identified as a potential economic driver via the strengthening of a local creative economy.

The National Economy and Social Development Board (NESDB) of Thailand define a creative economy as 'an economic system that mixes cultural assets, local wisdom, and the uniqueness of Thai with proper knowledge and technology in order to produce unique and diverse products and services. In this way, intrinsic economic value will be added. It will create jobs, generate revenue, and boost competitiveness that will enhance the quality of life. It defines creative industries as 'those industries which use Thai-ness, culture, heritage, and local wisdom, as well as technology, for economic development.' (Howkins, 2010)

From a global perspective, the creative economy is one of the fastest growing sectors of the current world economy, with a calculated worth of US\$2.2 trillion worldwide in 2002, and an annual growth rate of 5\%. This economy has the potential to produce dramatic results in terms of income generation, job creation, and export earnings, as well as engender non-monetary value that is critical in attaining inclusive, sustainable development. The creative economy is multi-faceted, comprising cultural goods and services, toys and games, and the Research and Development (R\&D) sphere. Thus, the economy is driven by creative processes of a varied sort, with some falling within traditional ideas of "cultural" activities, and others in a more diverse realm.

The creative economy in Thailand is divided into four sectors. The first sector highlights Thai cultural inheritance, and includes cultural tourism, as well as traditional medicine, herbs, spas, and food. The second sector focuses on the skilled labor and cultural arts industry, such as woodwork, handicrafts, sculpting, ceramics, silver and goldsmithing, and jewelry design. The third sector promotes creative work and design, specifically fashion, architecture, advertising, and software. The final sector is composed of the modern media, including entertainment and digital content.

In Thailand's $11^{\text {th }}$ National Economic and Social Development Plan (2012-2016) the creative economy is specifically mentioned as a way to promote economic structural adjustments, particularly in the production and service sectors, which would add value and generate new business by tapping into the hidden potential of Thai society. The decision to advance the country using the creative economy represented a major shift in both Thai and Lan Na society. However, the development model is congruent with the Thai and Lan Na culture and way of life and aligns with the "Sufficiency Economy" philosophy initiated and developed by His Majesty King Rama the IX.

In the past, government plans have sometimes failed to align these strategic goals with the realities of individuals and markets, which could be related to the creative economy's heavy reliance on tacit knowledge. Thus, a key to successfully developing a thriving creative economy is by translating this tacit knowledge into explicit knowledge, which this research aims to do in part by understanding more about the integration of the creative class into the local creative economy.

All creative economies need a creative class to drive the system. The creative class is mostly composed of migrants to Chiang Mai. While college graduates have the highest mobility of all, workers with a community-college education are less mobile, high school graduates are even less and dropouts are the least mobile of all. When the creative class migrates to creative cities, there is some evidence that they are unable to integrate with local people, particularly in cases where large projects are implemented without a clear understanding of the local culture and interests. The objective of this study is to classify a local integration model of the migrant creative class and to suggest a set of indicators that could be used to measure the successful integration of a migrant creative class when building creative cities, especially in Chiang Mai, Thailand.

\section{Literature Review}

This section will examine the Creative Economy, Creative Class, and the Local Integration model, which is used in this study as follows: 


\subsection{Creative Economy}

The creative economy, an economy that utilizes knowledge, skill, and culture to drive change and innovation, has become a key factor in the national development of more than 100 countries worldwide. In focusing on creativity as the source of both personal fulfillment and economic development, the creative economy marks a shift from previous economic systems that tended to devalue personal involvement in work (Howkins, 2013).

Creative cities are a space in which the creative economy can thrive; these cities fuse diverse cultural activities into social and economic functions. Unlike cities where development is mainly driven by factors such as natural resources, geographic location, or market access, creative cities rely on creativity. Such cities are marked by a robust social and cultural infrastructure, which tends to attract internal investment and elevate levels of creative employment. Creative cities depend on identifying, attracting, developing, and maintaining talent, prioritizing creative skills and organizations in order to retain a gifted, creative class (Landry, 2006).

\subsection{Creative Class}

Florida (2003) stated that the "creative class" is composed of people in fields including science and engineering, architecture and design, education, and arts, music and entertainment, whose economic objective is to develop new ideas, new technology, and new creative content. The creative class is essential and highly prized in the current economic environment, advancing new fields such as social media and innovating existing sectors like medical research.

Florida also asserts that economic development is largely driven by lifestyle factors, including urban infrastructure, tolerance and diversity, and entertainment. For cities to attract a creative class, he argues that the city must possess and promote factors such as talent, technology and tolerance (Florida, 2003).

Previous social science research on regional growth and development has primarily focused on the role of firms in urban areas, especially regarding how firms decide on location, and to what extent they cluster in specific areas. However, this research does not necessarily correlate with the motivations of the creative class. Florida suggests that conceptual refocusing and broadening beyond solely examining firms may be necessary in order to incorporate the location decisions of the people composing the creative class, and therefore more fully understand sources of economic growth (Florida, 2003), (Rambely, 2013).

\subsection{Local Integration Model}

Integration is the process of achieving harmonious relationships and close coordination between several people, groups, or organizations, while an integration model is a model that describes how individuals integrate into a specific social environment.

Indicators of integration compose a framework that explores the process of migrant integration with local people through interrelated "domains" (Ager \& Strang, 2004). Under each domain are indicators to measure the level of success in integration. The framework serves two purposes; first, to examine different understandings of the idea of "integration," and second, to establish a framework for a common understanding of "integration" that can be utilized by those working in the field of migrant integration in Lan Na.

\subsection{Knowledge Based Society}

The European Research Area (ERA) (2009), a European Commission program, is using knowledge as its fundamental base by which to achieve leadership, jobs, and growth in their countries. A knowledge-based society is created through a strong interaction within the "Knowledge Triangle" of research, education, and innovation. Innovative policies relating to each element are jointly designed by public authorities at all levels with the appropriate involvement of relevant stakeholders to optimize their effectiveness, efficiency and value to society and the economy.

This study applies the "Knowledge Triangle" to Lan Na society and views the roles of "researcher," "educator," and "innovator" within Lan $\mathrm{Na}$ as part of the creative class that drives the creative city of Chiang Mai. 


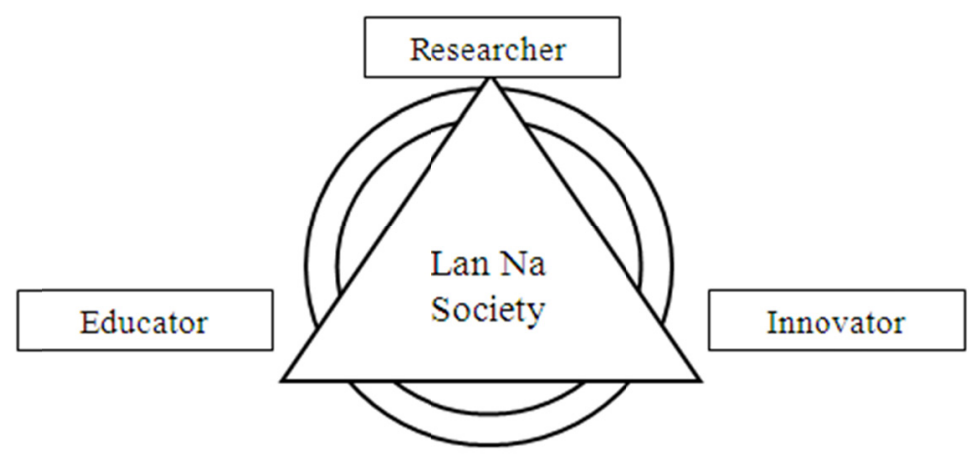

Figure 1. Creating a Lan Na knowledge-based society (Ref: Applied from The European Research Area (ERA))

\subsection{Ontology}

Ontology is a branch of philosophical study that examines the nature of being, the basic categories of being, and their relations. Ontology describes the concepts and relationships that exist for a specific set of entities, including how those entities may be grouped, placed within a hierarchy, or further divided (Jonathan Chacon et al., Paolo Ciccarese et al. 2010, and Cui Guangzuo). For the purposes of this study, annotation ontology was used to identify the local integration strategy of the creative class migrants.

\section{Research Methodology}

\subsection{Stage I: Sample Selection}

This study selected twelve creative class sample cases from migrants coming from areas outside of Chiang Mai who migrated more than five years ago. The sample cases are well-known individuals in Chiang Mai who are recognized as part of the city's creative class. The sample cases are separated into three groups following the roles identified in the knowledge-based society triangle; namely, educator, researcher, and innovator

\subsection{Stage II: Set Agenda}

The set agenda included in-depth interviews with creative class sample cases. The interviews utilized open-ended questions with a semi-structured format to collect personal data. The questions followed the local integration ontology model as shown in Figure 2.
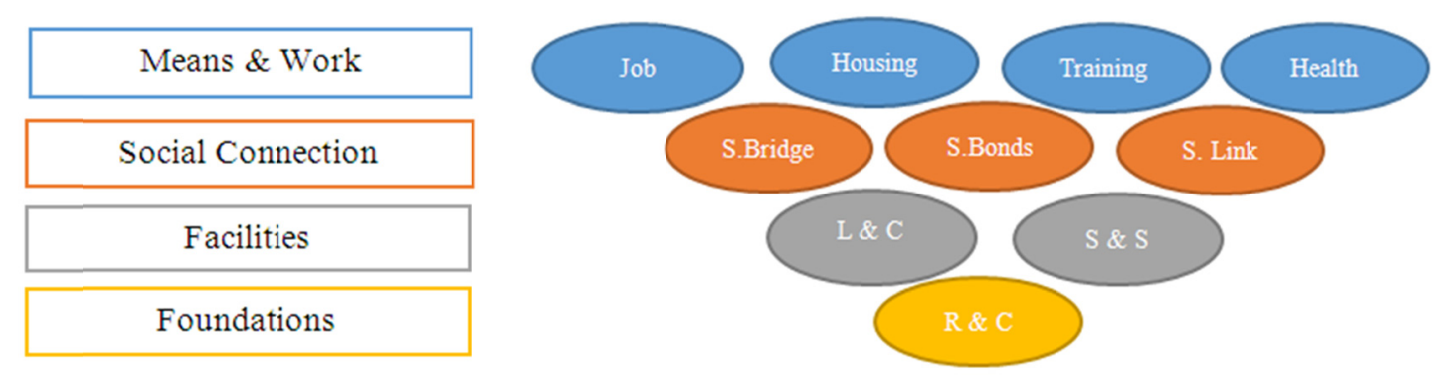

Figure 2. Local Integration Ontology Model

A brief description of each framework is as follows:

- Means and Work: There are four domains within the framework under 'Means and Work.' The first is "Job," and specifically pertains to an occupation related to Lan Na. The second domain is "Housing," which details the location of housing, how the location was selected, as well as how the sample became part of the local culture. The next domain is "Training," which focuses on Lan Na knowledge, and Lan Na training. The final domain is "Health," which covers both adaptability in a Lan Na environment, and holistic health in the Lan Na style.

- Social Connections: These are the most important factor for local integration, as most approaches to integration understand a sense of belonging to a particular group or community is crucial. There are three 
domains within the framework under 'Social Connections.' "Social Bridge" is related with work, national, ethnic or religious groupings, while "Social Bonds" are related to family matters. "Social Link" pertains to engagement with local government and non-governmental services, civic duties, and the political process.

- Facilities: There are two domains within the framework under 'Facilities'-"Language and Cultural Knowledge," which relates to dress, lifestyle, and food, and "Safety and Stability," which focuses on personal security.

- Foundations: There is only one domain in the foundations framework-"Rights and Citizenship," which pertains to voting and also identification with the Lan Na way of life.

\subsection{Stage III: Knowledge Elicitation}

In this study, in-depth interviewing was used as a method of gathering data from sample cases. In-depth interviewing is suited for eliciting descriptions of processes and outcomes from the samples. The goal of in-depth interviews is to deeply explore the respondent's point of view, feelings, and perspectives, and these can be used to obtain preliminary information that is necessary to develop more concrete quantitative surveys.

The researcher made an appointment with each creative class sample case before interviewing the sample case by case. During the interviews, the researcher recorded data and observed the sample cases.

\subsection{Stage IV: Transcribe}

Following the in-depth interviews with the creative class sample cases, all results were transcribed using a concept map. A concept map represents relationships between ideas and images, and develops logical thinking. Concept maps are constructed to reflect the organization of the declarative memory system, and facilitate sense-making and meaningful learning on the part of individuals.

\subsection{Stage V: Annotation Ontology (AO)}

In this study, Annotation Ontology (AO) uses local integration ontology for identifying the local integration strategy of the creative class migrants. The researchers designed this to extensively reuse existing domain ontologies and to provide several other kinds of annotations such as comments, textual annotation, notes, and examples on potentially any kind of document. The researchers analyzed the annotation ontology from the results script following the local integration model (Figure 2).

\section{Results Analysis}

\subsection{Stage I: Sample Selecting}

Chiang Mai's status as a hub city with excellent infrastructure and many universities, and without the chaos of the national capital of Bangkok, draws many new migrants each year. The twelve sample cases in this study were selected from a migrant population who had migrated from areas outside of Chiang Mai and neighboring Lampoon province more than five years ago. All of the sample cases are well known in Chiang Mai.

The sample cases are separated into three groups (Table 1). The first group is composed of educators, people who teach in the university or are academics in Chiang Mai. The second group is made up of researchers; people who conduct research that in this case, is specifically related to Lan Na. The third group is composed of innovators, people who introduce, develop or create products or services with improved or advanced quality. Some sample cases fulfilled both educator and researcher roles, some fulfilled both educator and innovator roles, and others played all three roles. The integration of these three groups, which are also represented as different elements of the knowledge triangle, is key in being able to concentrate, visualize and advance creative cities by bridging gaps and accelerating the interplay between academia, industry and society.

Table 1. Creative class sample cases

\begin{tabular}{lllllllllllll}
\hline Cases & 1 & 2 & 3 & 4 & 5 & 6 & 7 & 8 & 9 & 10 & 11 & 12 \\
\hline Educator & $\mathrm{X}$ & $\mathrm{X}$ & $\mathrm{X}$ & $\mathrm{X}$ & $\mathrm{X}$ & $\mathrm{X}$ & & & $\mathrm{X}$ & & $\mathrm{X}$ & \\
Innovator & & & & $\mathrm{X}$ & & $\mathrm{X}$ & $\mathrm{X}$ & $\mathrm{X}$ & $\mathrm{X}$ & $\mathrm{X}$ & $\mathrm{X}$ & $\mathrm{X}$ \\
Researcher & $\mathrm{X}$ & $\mathrm{X}$ & $\mathrm{X}$ & $\mathrm{X}$ & $\mathrm{X}$ & $\mathrm{X}$ & & & $\mathrm{X}$ & & & \\
\hline
\end{tabular}




\subsection{Stage II: Set Agenda}

Following the sample selection, the semi-structured format for the in-depth interview was divided into four groups following the local integration ontology model. The open-ended questions were coded as follows:

- Means and Work: inquiring about

MW1-Job,

MW2-Housing,

MW3-Training, and

MW4-Health, which relates to Lan Na,

- Social Connections: inquiring about

SC1-Social Bridge,

SC2-Social Bonds, and

SC3-Social Link,

- Facilities: inquiring about

FA1-Language and Cultural Knowledge

FA2- Safety and Stability,

- Foundations

FD1-Rights and Citizenship.

\subsection{Stage III: Knowledge Elicitation}

The researcher made individual interview appointments and informed the creative class sample cases about the agenda prior to the actual interview. During the in-depth interview, the researcher inquired about their background and was guided by the agenda in conducting the inquiry. The result of the in-depth interview found that each migrant sample case had different backgrounds relating to means and work, social connection, facilities, and foundation. However, the sample all shared a similar purpose, which was to continue to live in Chiang Mai due to their connection to, interest in, and love of Lan $\mathrm{Na}$ Society.

\subsection{Stage IV: Transcribe}

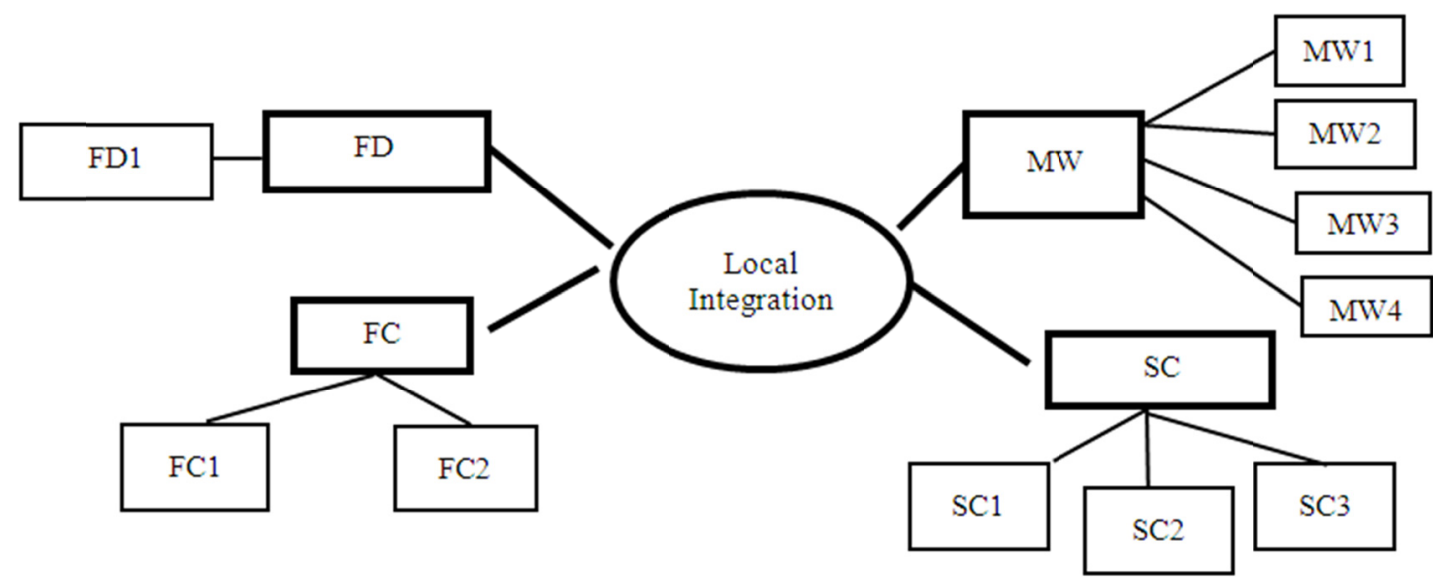

Figure 3. Concept map of local integration model

\subsection{Stage V: Annotation Ontology (AO)}

After transcribing the information from the migrant sample cases with the concept map, Annotation Ontology (AO) was used for dividing the domains. The content of each domain was defined and further detailed making use of the relevant keywords from the local integration model, and is described below.

- $\quad$ Means \& Work 
Table 2. Annotation ontology of migrants in means \& work

\begin{tabular}{|c|c|c|c|c|}
\hline \multicolumn{5}{|l|}{ MW (Means \& Work) } \\
\hline MW-1 (Job) & MW-2 (Housing) & MW-3 (Training) & & MW-4 (Health) \\
\hline $\begin{array}{ll}\text { Lecturer } & \text { (Government } \\
\text { Organization-GO) } & \end{array}$ & City (Location-LOC) & $\begin{array}{l}\text { University } \\
\text { LERN) }\end{array}$ & (Learn- & $\begin{array}{l}\text { Eat local food (Food \& } \\
\text { Drink-F\&D) }\end{array}$ \\
\hline Architecture (Business-B) & Urban (LOC) & $\begin{array}{l}\text { Join in seminar, } \\
\text { (Seminar-SEM) }\end{array}$ & meeting & Local drink (F\&D) \\
\hline $\begin{array}{l}\text { Researcher (GO/Non-government } \\
\text { organization } \mathrm{NGO})\end{array}$ & $\begin{array}{l}\text { Participate with community } \\
\text { (Activities-ACT) }\end{array}$ & $\begin{array}{l}\text { Learning by } \\
(\mathrm{LERN})\end{array}$ & Doing & $\begin{array}{l}\text { Take care of themselves } \\
\text { (Holistic-HOL) }\end{array}$ \\
\hline Columnist (B) & Love (Reason-RES) & $\begin{array}{l}\text { Talk with } \\
\text { (Interview-INT) }\end{array}$ & experts & Retreat (Wellness-WN) \\
\hline Civil (NGO) & Family (RES) & $\begin{array}{l}\text { Join and look to } \\
\text { (Observe-OBS) }\end{array}$ & experts & Herb/ herb product (WN) \\
\hline Editor (B) & & & & $\begin{array}{ll}\text { Fon } & \text { Cheng } \\
\text { (Exercise-EXE) } & \end{array}$ \\
\hline
\end{tabular}

From analyzing data using Table 2, it was clear that most migrants work as lecturers in the university, in some cases teaching Lan $\mathrm{Na}$ history. Some educators also work as researchers, and study Lan $\mathrm{Na}$ related issues. Innovators work in professions requiring creative ideas, such as an architect, designer, and editor. They work with government organizations such as universities (GO), non-government organizations like civil society groups or a Lan Na school of traditional wisdom (NGO), or in a self- or company-owned business (B).

Within the housing domain, sample cases were asked about their accommodation and chosen physical location (LOC), and the results revealed that some of the creative class migrated to Chiang Mai due to a love of the culture, traditions, nature, lifestyle, and local people. Others in the creative class migrated for family reasons (RES), for example, marriage. Most of them are located in Chiang Mai city and in the nearby vicinity where they can engage in creative ideas and participate in local activities (ACT) in a community around their home.

In the training domain, it was found that creative class sample cases were successful in learning (LERN) about Lan $\mathrm{Na}$ through experiential learning opportunities, talking (INT) with Lan $\mathrm{Na}$ experts to benefit from local wisdom, or studying Lan $\mathrm{Na}$ at university. They also make connections with local people and observe Lan $\mathrm{Na}$ customs and traditions in practice (OBS). All of them participate in seminars and meetings about Lan Na (SEM), such as the Lan $\mathrm{Na}$ lifestyle or Lan $\mathrm{Na}$ language.

Within the health domain it was found that migrant sample cases were able to adapt their lifestyles to the Lan $\mathrm{Na}$ environment (HOL). They use Lan Na holistic wisdom for wellness and in retreats, such as Lan Na massage, Lan $\mathrm{Na}$ exercise (EXE), and Lan Na herb products. They consume and enjoy local food and drink (F\&D).

\section{- $\quad$ Social Connections}

Table 3. Annotation ontology of migrants in social connection

\begin{tabular}{|c|c|c|}
\hline \multicolumn{3}{|l|}{ SC (Social Connection) } \\
\hline SC-1 Social Bridge & SC-2 Social Bonds & SC-3 Social Link \\
\hline University (Work-WORK) & Married (Family-FAM) & City Hall (Local Government Organization-LGO) \\
\hline Own Business (WORK) & & University/ School (LGO) \\
\hline Buddhist (Religion-REL) & & Organization (Local Non-Government Organization - LNGO) \\
\hline \multirow[t]{2}{*}{ Local People (Ethnic-ETN) } & & Association (Civil-CIV) \\
\hline & & Club (CIV) \\
\hline
\end{tabular}

The study in social connections (Table 3) found that the migration of educators is related with work in the university (WORK), which was also a social bridge for new migrants. In other cases, the main migration purpose was due to a social bond such as marriage (FAM) with local people and a subsequent move to Chiang Mai. All of 
the sample creative class is Buddhist (REL), which is also the predominant religion of Lan $\mathrm{Na}$, and following their migration to Chiang Mai it was easy for them to join Buddhist activities in their community. They can join with local people (ETN) in various ways. In relation to social links, it was found that all sample cases engaged in Chiang Mai City Hall, university, and school (LGO) in Chiang Mai. They also participated in many organizations (LNGO), associations and clubs (CIV), holding roles such as president, consultant, committee member, and member of these groups.

- Facilities

Table 4. Annotation ontology of migrants in facilities

\begin{tabular}{ll}
\hline FC (Facilities) & \\
\hline FC1-Language and cultural knowledge & FC2-Safety and Stability \\
\hline Speaking, Listening, Reading, Writing (Language-LAN) & Safety in Lan Na (Safety-SAFE) \\
Dressing in Lan Na (Dress) & \\
Collecting textile (Dress) & \\
Activities (ACT) & \\
Source of culture (Knowledge Management-KM) & \\
\hline
\end{tabular}

The results from the facilities domain detailed in Table 4 found that the language and cultural knowledge reported by the sample includes information that is useful for daily life, such as understanding and practicing spoken and written Lan Na language, which is still used regularly in Chiang Mai (LAN). The sample lived a Lan $\mathrm{Na}$ influenced lifestyle, learned about Lan Na culture from local people and trainings, and also dressed (DRESS) in the Lan Na style, in some cases even collecting (DRESS) Lan Na textiles. There are many cultural activities that the creative class sample cases can partake in with the community (KM), such as celebrate new home. For safety and stability (SAFE), community safety is a common concern amongst migrants in a new area. However, all of the migrant sample cases reported feeling safe and secure in Chiang Mai because of the city's strong infrastructure and low rates of violent crime.

- Foundation

Table 5. Annotation ontology of migrants in foundations

\begin{tabular}{l}
\hline FD (Foundations) \\
\hline FD1 (Rights and citizenship) \\
\hline Proud to be Lan Na (Proud-PROUD) \\
Election in Chiang Mai (Election-ELEC) \\
Feel dissimilar with speaking language (PROUD) \\
\hline
\end{tabular}

The study of the foundations domain in Table 5 found that the migrant creative class sample cases are proud (PROUD) to be Lan Na people. They often present as Lan Na people despite their migrant status, and at times feel offended if someone tells them that their Lan Na accent is incorrect. In terms of political integration, most of the sample are registered (ELEC) in Chiang Mai and vote there, and did not report any problems with rights and citizenship.

\section{Analysis Using the Local Integration Ontological Model}

This study aims to classify a local integration model of the migrant creative class and to suggest a set of indicators that could be used to measure the successful integration of a migrant creative class when building creative cities, particularly in Chiang Mai, Thailand. The study found that the local integration model consisted of four key domains: means and work, social connection, facilities, and foundations. All four domains are necessary for the local integration of the creative class in creative cities.

Each domain also included significant factors. Significant factors within the means and work domain are jobs, housing, training, and health. Significant factors within the social connection domain are the social bridges, 
social bonds, and social links. In the facilities domain, significant factors include language and cultural knowledge and safety and stability. The significant factor in the foundations domain is rights and citizenship.

Further analysis found that many domains link with others. Job in the means and work domain links to social link in the social connection domain. Activities in housing link with activities in the facilities domain. Housing in the means and work domain links with social bonds in the social connection domain.

This study uses Annotation Ontology to classify the integration model and find the most important factors for success for migrants in creative cities. The four most important factors are job, training, social bridge, and language and culture knowledge. A good job helps migrants meet with people engaged in similar professional activities who can help them begin to assimilate into a community. Training opportunities ensure that migrants who are attentive and interested in their new society will be able to access various types of Lan Na knowledge that they can then use in their daily lives. The social bridge, such as a migrant's work, national, ethnic or religious group, provides the opportunity for regular connection with other individuals or groups with similar interests or beliefs. Finally, migrants who are familiar with the language and cultural knowledge of their new society will face less social barriers and integrate more easily with local people.

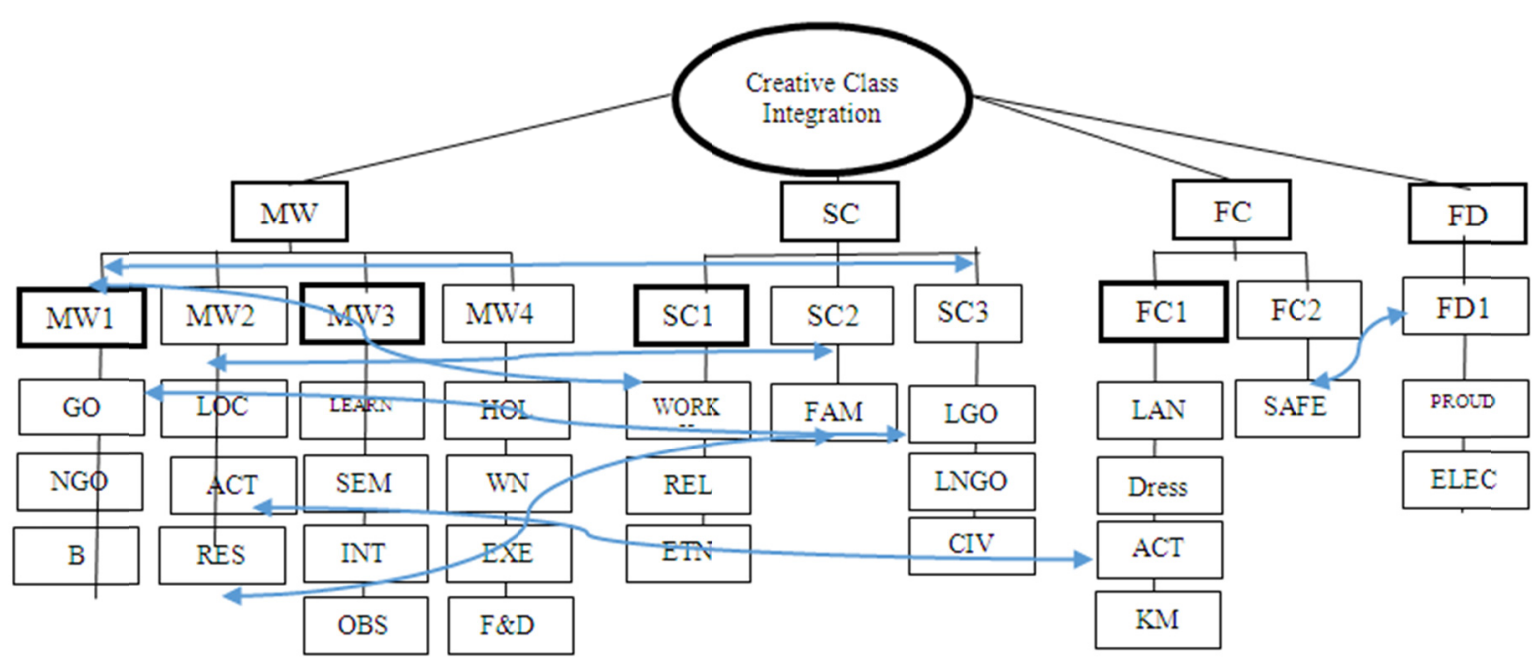

Figure 4. Mind map of Lan Na local integration metric

\section{Discussion and Conclusion}

The creative class sample cases in this study were successful in their work to the point where they were recognized by other local people for their achievements. The entire set of sample cases shared some distinctive similarities that were helpful to their successful integration; they are employed in good jobs in government organizations, non-government organizations, and in businesses. They are interested in Lan Na culture and holistic wellness, and join in traditional and local activities. They have good social connections with others, and are proud to be Lan Na people and vote in Chiang Mai.

This study found that the use of local integration ontology is beneficial in classifying important integration factors for the migrant creative class. The understanding of how migrants in the creative class successfully integrate in Chiang Mai specifically is gained using the new Lan Na Local Integration Metric applied in this study. This metric is quite different from the Local Integration Metric, and can be used to help the creative city of Chiang Mai know the factors necessary for the positive integration of the creative class, which is critical in driving the creative economy. Additionally, the Lan Na Local Integration Metric can be used as an example for other creative cities looking to refine a Local Integration Metric to specifically apply to their creative class.

\section{References}

Ager, A., \& Strang, A. (2004). Indicators of Integration: Final Report. Home Office, Research, Development and Statistics Directorate.

Chacon, J., Hernandex-Leo, D., \& Blat, J. (2011). From a Pattern Language to a Pattern Ontology Approach for 
CSCL Script Design. Computational Science and Its Applications-ICCSA 2011. International Conference Santander (pp. 547-561), Spain. http://dx.doi.org/10.1007/978-3-642-21898-9_45

Ciccarese P., Ocana M., Castro, L. J. G., Das, S., \& Clark, T. (2011). An Open Annotation Ontology for Science on Web 3.0. Journal Biomed Semantics, 2(Suppl 2), S4. http://dx.doi.org/10.1186/2041-1480-2-S2-S4

Florida, R. (2002). The Rise of the Creative Class and How it's Transforming Work, Leisure, Community and Everyday Life. New York, Basic Books.

Florida, R. (2003). Cities and the Creative Class. City and Community, 2(1), 3-20. http://dx.doi.org/10.1111/1540-6040.00034.

Guangzuo, C., Fei, C., Hu, C., \& Shufang, L. (2003). OntoEdu: A support platform based on ontology teaching. The third conference of high school teaching technique constitution institute (pp. 238-246).

Hansen, H., \& Niedomysl, T. (2009). Migration of the creative class: Evidence from Sweden. Journal of Economic Geography, 9, 191-206. http://dx.doi.org/10.1093/jeg/lbn046

Howkins, J. (2010). Thailand's National Strategy on Creative Economy. Office of the National Economic and Social Development Board \& United Nations Development Programme.

Howkins, J. (2013). The Creative Economy: How people make money from ideas. London: Penguin.

Landry, C. (2006). The Creative City: A toolkit for urban innovators. London: Earthscan. http://dx.doi.org/10.4324/NOE0415232418.ch17

Lovett, C., \& Beesley, K. (2007). "Where to live? The residential preferences of Canada's creative class" Prairie Perspectives: Geographical Essays. North Dakota, University of North Dakota.

Palen, J. (2011). The Urban World (9th ed.).

Rambely, A. S., Ahmad, R. R., Majid N., M-Suradi, N. R., Din, U. K. S., A-Rahman, I., . . Abu-Hanifah, S. (2013). Project-Based Activity: Root of Research and Creative Thinking. International Education Studies Journal, 6(6).

Srikam, W. (2007). Urbanization and Urbanism in Thailand. Journal of Urban Culture Research, 4, 36-50

World Bank (2015). Urbanization in Thailand is dominated by the Bangkok urban area. Retrieved from http://www.worldbank.org/en/news/feature/2015/01/26/

Yeates, M., \& Garner, B. (1976). The City, or the Myth? The North American City (2nd ed.). New York: Harper \& Row.

\section{Copyrights}

Copyright for this article is retained by the author(s), with first publication rights granted to the journal.

This is an open-access article distributed under the terms and conditions of the Creative Commons Attribution license (http://creativecommons.org/licenses/by/3.0/). 